\title{
Utility and challenges of 3 D Printing
}

\author{
Aman Sharma ${ }^{1}$, Harish Garg ${ }^{2}$ \\ ${ }^{1,2}$ (Department of Mechanical Engineering, DAV University, Jalandhar, Punjab)
}

\begin{abstract}
This paper is all about the advanced technology of $3 D$ printing, their implementation in the respective fields and its significant contribution in the global world of science and medical. In this paper we will deal with the term Additive Manufacturing or 3D Printing and a little bit of its history. Its various applications along with the type of materials used in the 3-D are also described. We shall also throw some light on the numerous opportunities provided by this emerging technology as well as the risks and challenges related to it. Its environmental aspects are also shown in the paper. Lastly the scope and scenario in future potential of $3 D$ printing is also evaluated.
\end{abstract}

Keywords : 3D Printing; Additive Printing; Fused Deposition Modeling (FDM); Stereo-lithography; ABS Plastics.

\section{INTRODUCTION}

3D printing can also be referred to as Additive Manufacturing. "Additive Manufacturing — Defined by ASTM International (ASTM 2792-12): Additive Manufacturing is a process of joining materials to make objects from three dimensional model data, usually layer upon layer, as opposed to subtractive manufacturing methodologies. As a new tool in the entrepreneurial toolbox, additive manufacturing system use computer- aided design models and 3D scanning systems for production.[1]This technology has changed the world of manufacturing. Today any tool can be developed by simply making a $3 \mathrm{~d}$ model of it or by scanning it with a $3 \mathrm{~d}$ scanner and then just click on "print" and then object can be seen taking shape from a digital to the physical reality.

The AM process begins with a 3D model of the object created with the help CAD software or a 3D scanner. AM printer then creates the object layer by layer using a suitable material. This material may vary from plastic to molten metal and compounds of carbon.

The first solid object was printed by the Hideo Kodama of Nagoya Municipal Industrial Research Institute. However it was mid 1980s when Charles Hull (Founder of 3D Systems) and Scott Crump (Founder of Stratasys) developed a range of technologies now known as 3D printing. Charles Hull is also the pioneer of the solid imaging process known as stereo lithography and STL (stereo lithographic) file format which has become one of the most widely used file formats for 3D software. [2]

\section{BASIC PRINCIPLES OF 3D PRINTING}

A 3D printer works on different technologies which are:

a. Stereolithography': It was invented by Charles Hull in 1986. In this method UV rays are concentrated on the surface of the object to be replicated which is made of photopolymer. As the rays strike the object, the required model is created.

b. Fused Deposition Modeling (FDM): It was patented by Stratasys. In this process, filament of plastic modeling material and soluble support material are fed from auto-loading carries in the material bay up to the extrusion head. There, the materials are heated to a semi-liquid state, forced through dual up to the extrusion tips and precisely deposited onto the modeling in extremely fine layers. The print head moves in $\mathrm{X}-\mathrm{Y}$ direction and the modeling base moves in the $\mathrm{Z}$-axis.

c. Selective Laser Sintering: In this technology powdered material is used instead of liquid resin. Nylon, ceramics, glass, aluminum, steel or silver.

d. Selective Laser Melting: In this process the powder material used in the printer is melted instead of combining them.

e. Electronic Beam Melting: 3D printers use the electron beam instead of UV rays. 
f. Laminated Object Manufacturing: In this process the plastic, paper, or metal are glued together and after that they are cut with laser to give them the desired shape.[3]

\section{CLASSIFICATION OF VARIOUS TYPES OF 3-D PRINTING}

Based on the fact that 3D printers work on various technologies, there are many types of printers available in the stores. These printers vary from expensive and multi-head printer to cheap printers which can be easily bought and used in homes and offices. They can also be classified on the basis of the type of materials used.

The different types of materials used are FDM Thermoplastics, Polyjet Photopolymer, WDW materials etc. Recently chocolate has also been used as a material in 3D printer. Other materials such as carbon compounds and combination of different element are also being tested.

Nowadays 3D printers are also used in the field of medical science to repair tissue cells and to replicate the body organs. Ears, kidney and heart vessels have already been made and in near future it may be possible to print a real 3D printed heart working on its own. 3D printers were earlier used by the engineers to make only the prototypes but with the betterment of the technology, these are now used to print finished products. Around $28 \%$ of the output of 3D printers is now the final product which is expected to rise to $50 \%$ by 2016 and to $80 \%$ by the year 2020. [4] In Australia a local community has created a 3D printing lab in a library so the community can understand the technology. [5] Some of the companies which manufacture 3D printers are Stratasys, Ultimaker, Zcorp, 3D Systems, BitsfromBytes, Dimension, EOS, MakerBot, Object and RepRap Project.

\section{APPLICATIONS OF 3-D PRINTING}

- 3D printing is being used to manufacture hearing aids since more than 10 years ago. It has shortened the duration between the demand and supply and also can print different hearing aid shells.

- Laser sintering method is used in the automobile industries such as BMW, Bentley and Rolls-Royce to produce cheap and strong automotive parts.

- Nowadays aircraft components are also using the technique of 3D printing to print some of its parts. This is because of the fact that these parts are stronger as well as lighter as compared to the parts manufactured by the traditional method.

- Airbus produced a door bracket for the A350-1000 in 2011 using Additive Manufacturing which were much lighter and stronger than the conventional bracket. [6]

- The U.S. government has saved \$3.8 million from 2004-2009 by using 3D printing in combination with the traditional manufacturing techniques.[7]

- Recently the lower jaw of a patient was completely replaced with an artificial jaw which was completely 3D printed. Titanium powder is used in this printing. These printed bones are even degradable and may be replaced by the body's own bone tissues. Here silicon is used instead of titanium. [8]

- An artificial human ear has already been developed by the scientists.

- A real 3D printed handgun was made in 2013. 15 out of 16 pieces of which were 3D printed. It was called as "Liberator". [9]

- Nike produced a part of a sports shoe, a plate, with the help of AM technique. While the production of prototypes is common. [10]

- A quite different military application of 3D printing is the creation of topographical models to provide better intelligence.

\section{WHY FDM TECHNOLOGY PREFFERED IN 3-D PRINTING OVER ALTERNATE} METHOD

3D printing is a faster and much less expensive process than the traditional method of manufacturing. It is also portable and can be transported anywhere round the world.

The waste products formation in the 3D printing is also much lesser than the alternate method. For a particular specialty part, 3D printing reduced the cost of manufacturing from $\$ 10,000$ to $\$ 600$, the build time from 4 weeks to 24 hours, and the weight of the object by $70-90$ percent.[12] 
IOSR Journal of Mechanical and Civil Engineering (IOSR-JMCE)

e-ISSN: 2278-1684, p-ISSN: 2320-334X

TABLE I. Part w.r.t FDM

\begin{tabular}{|l|l|l|}
\hline Part/Tool & FDM & Alternate Method \\
\hline End of arm robot & $\$ 600 / 24$ hours & $\$ 10,000 / 4$ weeks \\
\hline Automated turntable & $\$ 8,800 / 2$ weeks & $\$ 50,000 / 8$ weeks \\
\hline Steel plates & $\$ 20 / 2$ hours & $\$ 200 / 2$ weeks \\
\hline
\end{tabular}

[13]

In fact this is the only technique through which a common person can create things of his own choice which are not availabiele in the stores. The acquisition cost of a 3D printer can be as little as $\$ 15,000$ (USD) versus as much as $\$ 500,000$ for a rapid prototype machine, making a good option for companies of all sizes. The ABS (Acrylonitrile butadiene styrene) plastic used in 3D printers is tested under the following conditions: Tensile Strength: $5300 \mathrm{psi}(37 \mathrm{MPa})$

Tensile Elongation: $3.0 \%$

Flexural Stress: $7600 \mathrm{psi}(3 \mathrm{MPa})$

IZOD Impact, notched: $5.0 \mathrm{ft}-\mathrm{lb} / \mathrm{in}(106 \mathrm{~J} / \mathrm{m})$

Heat Deflection: 204 F (96o C) [14]

The process of delivery of a product to a customer with an alternate method goes as follows:

The process of delivery of a product to a customer with an alternate method goes as follows:

DESIGN $\rightarrow$ PROTOTYPE $\rightarrow$ MANUFACTURE $\rightarrow$ ASSEMBLEY $\rightarrow$ DISTRIBUTION $\rightarrow$
WAREHOUSE $\rightarrow$ RETAIL ENPUSER $\rightarrow$
While the same process with 3D printer goes from IDEA toEND USER $\longrightarrow$

\section{ADVANTAGES OF 3-D PRINTING}

- Quicker And Proximity to Market. The longer the product stays in design cycle, the lesser is the profit to the company. Thus there is a requirement of fast production units which also produce tools with precise measurement. Thus $3 \mathrm{D}$ printers can provide such a fast rate of production to the companies.

- Cost Saving efficient and Economical. 3D printer uses mostly ABS plastic as a working material which reduces the cost of production to a great extent and also saves the raw materials which would be used in traditional method.

- Increased Data Security. Having a 3D printer at home removes any worry about the misuse of the confidential STL files which can then be safely sent to the vendor.

- More Rigorous Product Testing. Basically 3D printers were used only for printing models of the real objects which were much stronger and do not shrink or absorb moisture.

- Early Feedback identifies design flaws, defects and Discontinuities. As the output generated by the CAD software is very fast therefore it gives enough time to the user to identify any flaw if found in the design.

- Early Changes Saves Money. The cost of production increases if the changes are made in the later phase of the process. Thus it is necessary to communicate and collaborate with each other to reduce the cost of production.

\section{VARIOUS CHALLENGES WHILE INCORPORATING 3D PRINTING}

- Limitation in Speed: For large quantities of goods, AM would be difficult and require a considerable increase in speed of 3D printing.

- Materials: Research on the type of material to be used in 3D printing is still in process thus there is a limitation in the variety of materials that can be used.

- Real world proofing: Changes in temperature and atmospheric conditions can affect the 3D printing process. It may also require a skilled staff to run the 3D printer.

- Post-Processing: It is done manually and is an intense process. In case of medium or high production volume this might become an important matter. 


\section{FUTURE SCENARIO AND OUTLOOK}

- Food Beverages, drink and tobacco: In near future it may possible that the consumer would be consuming 3D printed foods in place of original meat and other edibles. A company named Modern Meadow has patented techniques that would 3D print the meat to be available in markets. The technology includes prepared multicellular aggregate delivered into a biocompatible support structure. [13]

- Wood and Paper: NASA has been developing technologies that would 3D print wood using bio-printing technique. This would enable the astronauts to bring wood into space without actually carrying it with them. [14]

- Metals and building materials: MIT Media Lab is experimenting on printing large moulds for concrete structures using spray poly-urethane foam. MIT has printed several wall moulds that are about 5-6 feet. Contour Crafting proposes 3D printing an entire house of 2,500 sq. foot within 20 hours with low cost and emergency housing system using a specially formulated concrete [15]

- Defense and Aerospace: Printing an aircraft wing may be possible in near future which may further lead to the development of an entire aircraft by this method. 3D printing on a battleship ground can bring a revolution as there would not be any dependence on the supply of ammos in the battlefield. Also self healing military vehicles can be developed.

- Automotive: 3D printed components for vehicles can be used whose models are rarely available in the market. Innovative vehicles enabled by 3D printing can also be manufactured.

- Healthcare: Tissue and organ transplant is also possible using 3D printed organs. Nano-Scale medicines can be produced along with complex printed organs.

- Consumer-Retail: 3D printing stores can be opened where a customer can express his ideas and accordingly the product can be printed.

- General Manufacturing: Printed electronics embedded in parts may be very common in future. Also factories may comprise of $3 \mathrm{D}$ printing machines along with or without the traditional manufacturing machines.

- Supply Chain management: Demand of powdered Titanium may increase. Also a scenario of direct supply may come into existence where designs are shipped and not the products.

\section{CONSIDERATION OF ENVIRONMENTAL ASPECTS WHILE IMPLEMENTING 3D PRINTING}

Two major factors affecting the Cumulative Energy Demand (CED) of 3D printed Products are: Choice of the material for printing and the amount of material used in manufacturing a product. Observations shows that $3 \mathrm{D}$ printed products consume less energy as they require less material. A shift to plastics and metals might occur resulting in potentially higher energy demands. 3D printer uses a material which is essential for the formation of the product, therefore negligible or very less waste is produced. The product formed is lighter in weight and thus less fuel is required. There is a community called RepRap which makes self-replicating printers and are focused on mainly recycled waste materials and are economically cheaper.

\section{REFERENCES}

[1] Bernard, A. and Fischer, A. ,New trends in rapid product development, CIRP Annals - Manufacturing Technology , Vol. 51, pp. 635652, 2002.

[2] Birtchnell, T. and Urry, J., "3D, SF and the Future”, Futures ,2013, Vol. 50, pp. 25-34.

[3] Council, A. and Petch, M., 3D Printing: Rise of the Third Industrial Revolution ,Gyges, Tumwater, 3D, 2014, p. 116.

[4] Jacobs, P.F., Stereo Lithography and other RP\&M Technologies: From Rapid Prototyping to Rapid Tooling ,Society of Manufacturing Engineers (SME), Dearborn, 1996, p. 450

[5] Huang, S.H., Liu, P., Mokasdar, A. and, and Hou, L. , Additive manufacturing and its societal impact:a literature review, International Journal of Advanced Manufacturing Technology, Vol. 67 Nos 5/8, 2013, pp. 1191-1203.

[6] Birtchnell, T. and Urry, J., 3D, SF and the Future, Futures, Vol. 50, 2013, pp. 25-34.

[7] Young, D., Sampath, S., Chikov, B. and Chrisey, D.B.,The future of direct writing in electronics, CircuiTree, Vol. 2,2005. 
[8] Masood, S.H.,Advances in Rapid Manufacturing and Tooling, Comprehensive Materials Processing, Elsevier Science Direct, Glasgow, pp. 69-91, 2005.

[9] Hull, C., Apparatus for production of three-dimensional objects by stereolithography, US Patent 4,575,330, 1986.

[10] Rodriguez, J.F. , Thomas, J.P. and Renaud, J.E. , Mechanical behavior of acrylonitrile butadiene styrene fused deposition materials modeling, Rapid Prototyping Journal, Vol. 9 No. 4, pp. 219-230, 2003.

[11] Pearce, J.M. , Morris Blair, C. , Laciak, K.J. , Andrews, R. , Nosrat, A. and Zelenika-Zovko, I. , 3-D printing of open source appropriate technologies for self-directed sustainable development, Journal of Sustainable Development, Vol. 3 No. 4, pp. 17-29, 2010.

[12] Durgun, I. and Ertan, R. ,Experimental investigation of FDM process for improvement of mechanical properties and production cost", Rapid Prototyping Journal, Vol. 20 No. 3, pp. 228-235, 2014.

[13] Bernard, A. and Fischer, A. ,New trends in rapid product development, CIRP Annals - Manufacturing Technology, Vol. 51, pp. 635652, 2002.

[14] Smith, W.C. and Dean, R.W. , Structural characteristics of fused deposition modeling polycarbonate material, Polymer Testing, Vol. 32 No. 8, pp. 1306-1312, 2013.

[15] Crump, S. ,Apparatus and method for creating three-dimensional objects, US Patent 5,121,329, 1992. 